\title{
Processo analítico e alteridade ${ }^{1}$
}

\author{
Talya S. Candi ${ }^{2}$
}

\section{O objeto analítico : a terceiridade como processo}

Segundo o psicanalista francês André Green a modernidade no âmbito da psicanálise surge pela conjunção de duas fontes. Por uma lado as contribuições decisivas dos autores pósfreudianos (particularmente M. Klein, W. Bion, J. Lacan e D. W. Winnicott) à teoria freudiana e, por outro lado, os novos horizontes da epistemologia cientifica do final do século XX particularmente os que abraçam dentro da sua teoria a complexidade e os paradoxos (E. Morin, G. Edelman, I.Matte-Blanco ). A psicanálise contemporânea se encontra assim no cruzamento destas duas velhas novidades que ao possibilitar reunir diferentes tradições pós-freudianas num conjunto coerente nos permite falar em terceira tópica . Esta nova tópica contempla tanto as teorias da relação de objeto como as que enfatizam o lado do sujeito freudiano da pulsão desfazendo assim antigas oposições entre o dentro e o fora , o intra-psíquico e o intersubjetivo possibilitando ampliar a reflexão acerca de velhos problemas . A teórica psicanalítica não pode no entanto se afastar da pesquisa clinica inerente à produção do pensamento em psicanálise, a clinica desperta inquietações e exige constantemente um processo de elaboração dos afetos. Para Green, não existe apenas uma teoria psicanalítica da clínica ${ }^{3}$, mas um pensamento clínico. Este último decorre de um modo específico e original da elaboração teórica produzida pelo contato vivo com a experiência analítica. Esta racionalidade particular, surge a partir da per-laboração da atividade fantasmática do analista relativa à transformação dos movimentos afetivos que se manifestam ao longo da sua escuta. Ao se configurar no movimento de uma escrita, o pensamento clínico é caracterizado por sua capacidade de convocar no participante uma linha associativa de representações e de evocar uma experiência afetiva relativa .

\footnotetext{
${ }^{1}$ Este trabalho foi apresentado na mesa "Transferência e alteridade: desconcertos" com Ana Maria de Andrade Azevedo no eixo "Psicanálise e suas clinicas" no I Simpósio Bienal "O mesmo, o outro: Psicanálise em movimento" da Sociedade Brasileira de Psicanálise de São Paulo.

${ }^{2}$ Membro associado da SBPSP, Doutora em Psicologia Clínica pela PUC-SP.

${ }^{3}$ Para mais, remeto o leitor ao texto: GREEN, André.[1999] Pour introduire la pensée clinique in La Pensée Clinique. Paris: Odile Jacob, 2002.
} 
Estas perspectivas, clinica e histórica, inerentes ao pensamento de André Green, nos permitem escutar e acolher a complexidade das formações do inconsciente que como Freud percebeu rapidamente a partir das suas primeiras observações com as histéricas se manifesta como um reduto de irracionalidade e de atemporalidade que se alimenta de uma lógica complexa e paradoxal.

A psicanálise, ciência do inconsciente humano é por excelência o domínio das alteridades, alteridades internas ao sujeito (cuja paradigma é o próprio inconsciente) que o submetem, alteridades externas que o interpelam e o convocam. A essência do processo analítico para André Green reside na possibilidade sempre inquietante de entrar em contato com estas alteridades que possuem um potencial traumático. Diz ele: "Farei a hipótese de que o procedimento psicanalítico deveria aproximar-se da descoberta do Outro (interno e externo), e abrir a possibilidade de amar, se separar e se reencontrar, sem riscos catastróficos, mas sempre incluindo a incontornável eventualidade de ter que enfrentar um luto"4. Neste artigo, junto com André Green nos aproximaremos destas alteridades e dos seus destinos no decorrer do processo psicanalítico .

\section{Alteridade e o sujeito psicanalítico}

Seguindo a tradição freudiana, André Green pressupõe que a pulsão, matéria prima da sexualidade humana, é a matriz do sujeito psicanalítico. Ela se manifesta para o núcleo egóico arcaico como uma força cega ${ }^{5}$, uma urgência basicamente inapreensível e irrepresentável que procura vias de figurabilidade e representabilidade através das junções que ela consegue estabelecer entre diferentes modalidades representativas internas (tais como excitação, estados corporais, afeto, sensação, fantasias e traços perceptivos) e das ligações que vão se tecendo a partir da resposta ${ }^{6}$ que a realidade externa e os objetos primários lhe fornecem . As moções pulsionais enraizadas no Id são o patrimônio da vitalidade do sujeito , elas se manifestam como um caldeirão cadente , uma alteridade dolorida, excessiva na sua essência , que submetem o self e deixam o sujeito num desamparo radical.

\footnotetext{
${ }^{4}$ GREEN, André. L'idéalisation du processus analytique et sa problématique veritable. In RFP, Tome LXVIII, Paris, 2004, p. 1875.

5 "somos vividos por forças desconhecidas e incontroláveis "S. Freud O ego e O Id( p37)

${ }^{6}$ A noção de resposta chama convoca à noção responsabilidade, tema que de alguma maneira implica numa ética do cuidado .
} 
Estas forças pulsionais precisam tal como Freud sugeriu ser domesticadas e para tal convocam uma resposta que exige um trabalho psíquico por parte dos objetos primordiais . Este trabalho do objeto vai modular os excessos, dar representação à força e integrar as alteridades ao núcleo egóico incipiente do sujeito. ${ }^{7}$

Ora Lembremos que em 1923 no texto "O Ego e O id", Freud claramente se refere a duas categorias de forças distintas que incidem na constituição egóica, categorias que podem ser dividas em entidades internas ( Id, afeto) e entidades externas (Os outros materializados no Super ego , o Real, a cultura ). Para Green o sujeito freudiano se encontra submetido a duas alteridades que o assujeitam e o exprimem exigindo que ele se torne o operador ${ }^{8}$ de um incessante trabalho psíquico de objetalização e apropriação subjetiva tanto dos impulsos internos, como da Realidade externa .

Em relação ao teor e ao efeito destas alteridades sobre o sujeito, André Green dialoga com os desenvolvimentos teóricos do psicanalista J. Lacan, estes diálogos o levam a incorporar o conceito lacaniano de Outro .

Já nos primeiros textos de Lacan a noção de alteridade encontra-se plenamente presente. Num primeiro momento, a alteridade surge ligada ao pensamento inconsciente que ele define como o discurso do Outro. Como este outro discurso funciona? Como chegou e se infiltrou no sujeito? Lacan explica a estranheza destas formações apontando para o fato de que nascemos num mundo de discurso e linguagem que precede nosso nascimento. Assim, muito antes de uma criança nascer, existe um lugar para ela no universo lingüístico dos pais. Essas palavras, que refletem em muitos aspectos a inserção cultural da família, constituem para Lacan o Outro da linguagem (L'Autre du langage) que se converte em outros momentos da sua obra em o Outro como linguagem.

Para Lacan uma criança nasce num lugar pré-estabelecido no universo lingüístico dos pais e é dentro desse universo lingüístico que os desejos da criança serão moldados. Vemos que a afirmação de Lacan é radical pois para ele a criança não pode ter uma apropriação de si mesma antes da assimilação da linguagem. Ele se refere, portanto, à linguagem como aquilo que constitui o desejo inconsciente e conseqüentemente molda a subjetividade . Contudo, vale ressaltar que para Lacan a noção de sentimento - o afeto inconsciente - é errônea, pois, em

\footnotetext{
${ }^{7}$ No segundo capitulo do texto "O ego E O Id" Freud se pergunta: como uma coisa se torna Pré-consciente? e a resposta seria "vinculando-se às representações verbais que lhe são correspondentes ", Freud, (1923) Obras completas, Ed Imago (p34). Cabe dizer que as representações verbais provêem da realidade Externa, do discurso do Outro que atravessa o sujeito

8 "Concebo o sujeito como um operador falível e na maioria das vezes faltante, submetido ao trabalho psíquico. O sujeito trabalha. É tudo o que ele sabe fazer" GREEN, André. Répétition, Différence, Réplication en Relisant au Delá du Principe de Plaisir [1970]. In: La Diachronie en Psychanalyse. Paris: Ed. Minuit, 2000, p. 94.
} 
sua leitura, Freud afirmou que o recalcado é formado pelo que ele chamou de vorstellungs reprasentanz, traduzido para o português como representantes ideativos. Com base em estudos dos textos freudianos, Lacan traduziu o termo para o francês como repésentants de la représentation (representantes da representação) e concluiu que esses representantes podem ser igualados ao que na lingüística se denomina de significantes.

Os significantes são, para Lacan, recalcados e caem no inconsciente, onde estabelecem relações com outros significantes recalcados desenvolvendo uma rede complexa de ligações. Ao dizer que o inconsciente é estruturado como uma linguagem, Lacan aponta para o fato de que existiram relações entre os elementos inconscientes (os significantes lingüísticos), ligações estas que são semelhantes às que existem em qualquer sistema lingüístico.

O inconsciente lacaniano não é nada mais do que uma cadeia de significantes, tais como palavras, fonemas e letras, que se "desdobram" de acordo com regras muito precisas, sobre as quais o Eu não tem nenhum controle. O inconsciente é concebido por Lacan em si como Outro, um alteridade estranha e inassimilável. Ora antes da ordem simbólica que se instala com o surgimento do significante linguiístico, existe somente a dimensão do que Lacan chamou de O Real. O Real é o corpo biológico de uma criança antes do domínio da ordem simbólica. No curso da socialização, o corpo é progressivamente escrito e sobrescrito com significantes. Esta inscrição terá o poder de localizar o prazer em determinadas zonas, enquanto outras serão neutralizadas pela palavra e persuadidas a se conformarem com as normas sociais e comportamentais. Levando assim a idéia de Freud sobre a perversidade polimorfa às últimas conseqüências, Lacan acha possível ver o corpo de uma criança como uma zona erógena contínua, na qual não haveria zonas privilegiadas e nenhuma área onde o prazer estivesse circunscrito de início. O Real de Lacan é, assim, sem zonas e subdivisões. Ele é constituído por um tecido indiferenciado, entrelaçado de maneira a ser completo, não possuindo espaço entre os fios que formam a sua matéria.

A divisão do Real em zonas separadas é resultado da ordem simbólica que corta a fachada do Real, criando entidades distintas que organizam o corpo indiferenciado, puxando-o para dentro dos símbolos usados para descrevê-lo e desse modo conseguir aniquilar seu potencial traumático. Ao neutralizar o real o simbolismo cria a realidade, entendida como aquilo que é nomeado pela linguagem e pode, portanto, ser apreendido, pensado e falado. A 'construção social da realidade' implica num mundo que pode ser designado e falado com as palavras fornecidas pela linguagem. O que não puder ser dito na sua linguagem não é parte da realidade social, e a rigor não existe. Na terminologia de Lacan, a realidade é um produto da 
linguagem: a linguagem cria coisas que não tinham existência antes de serem cifradas, simbolizadas ou verbalizadas.

Contudo, o Real não deve ser entendido somente como anterior à letra, ele deve ser também compreendido como aquilo que ainda não foi simbolizado, que resiste à inscrição lingüística. Uma das faces do Real é a do trauma, evento imprevisível experimentado tão intensamente que não pode ter uma elaboração psíquica e, portanto, permanece como uma fixação ou um bloqueio, um tecido excessivamente fechado que não pode ser recortado pela ordem simbólica, impedindo a circulação livre das energias vitais e das representações

Neste sentido, parte do processo psicanalítico envolve claramente permitir ao paciente colocar palavras lá onde havia somente pura alteridade, e materiais que resistiram à simbolização até então. Na situação analítica, o aparelho verbal à disposição do paciente, o capacitará a transformar experiências primitivas traumáticas nunca (ou insuficientemente) verbalizadas.

André Green, próximo a Freud da segunda tópica , insistirá em pensar no sujeito psicanalítico tomado dentro da situação analítica por uma dupla alteridade, pois, aquém da alteridade que representa o Outro da linguagem, ele terá que se defrontar com o outro da anti-linguagem representado por uma força pulsional enraizada no corpo biológico. Existe, para Green, uma alteridade interna à alteridade que surge inevitavelmente pela heterogeneidade entre a pulsão e o objeto, entre as urgências do corpo e o estatuto singular desse Outro que pode prover alguma resposta. Lacan, segundo Green, optou pela solução de facilidade dizendo "o inconsciente é estruturado como uma linguagem", pois isto significava que o Outro poderá trazer uma resposta potencialmente "falante" à pulsão, reconstituindo uma linguagem no lugar do inconsciente. Para Green, é necessário manter aberto o espaço que separa a pulsão e o objeto, sustentando uma incompatibilidade radical entre a matéria-prima biológica que forma o amálgama pulsional e a do Outro que é colocado no lugar singular a partir do qual deve responder à reivindicação pulsional.

O fundamento da troca entre o objeto e a pulsão será encontrar uma compatibilidade lá onde, a priori, existia somente incompatibilidade. Mesmo que, como Lacan, se coloque a linguagem ao lado dos mal-entendidos, sempre teremos um entendimento básico que vem do uso das próprias palavras. Para Green, existe uma casualidade pulsional (uma meta-biologia) que não poderá ser traduzida segundo as normatizações dos processos linguísticos e que permanecerá como um núcleo interno estranho e outro. Assim, teremos segundo Green, que levar em conta uma dupla alteridade, a de si com as exigências de um corpo, ligadas ao pólo pulsional indizível e a de si com o Outro (o objeto) que se manifesta numa discursividade ordenada pelo desejo. 
Colocar em relação estas duas polaridades, intra-psíquica e intersubjetiva, constitui a essência do trabalho do negativo, que determina o trabalho feito pelo aparelho psíquico. Vale, contudo, ressaltar que, para Green, estamos num universo marcado por tudo que se opõe à totalização e à plenitude e onde um conflito originário resiste a todas as transformações possíveis realizadas pelo aparelho psíquico. Existe em todo pensamento greeniano uma força mortífera silenciosa que luta ativamente contra as ligações que o trabalho de simbolização realiza. Opondo-se assim ao processo do pensamento, esta força é presente de tal maneira que Green chega a se perguntar: "A vida é um acidente num fundo de morte permanente?".

\section{Processo analítico, objetalização e transformação}

Numa entrevista recente, André Green diz de maneira muito esclarecedora: "Com o tempo, o psiquismo no seu conjunto foi se configurando como nada mais do que uma formação tampão entre o soma pulsional e o Real, de tal forma que, se não fôssemos humanos, o choque frontal entre o soma e o real impediria qualquer diferenciação" 9 .

Assim num espaço intermediário entre os extremos deste espectro que vai da alteridade proveniente do completamente interno (pulsão) para a alteridade formada pelo completamente externo ( o Outro) encontramos a vida psíquica que se caracteriza por exercer as atividades do sonhar, do brincar e do pensar e que se desenvolve a partir da elaboração do impacto emocional e da simbolização . Estas atividades psíquicas acolhem a dor provocada pela passividade radical proporcionando uma maior mobilidade interna e a liberdade necessária para a criatividade humana. A vida psíquica se caracteriza por desenvolver um brincar criativo que tece vínculos possibilitando captar numa estrutura triangular as alteridades desligadas provenientes do mundo externo e interno, criando uma rede de re-apresentações e fantasias que amplia as potencialidades do processamento da vida emocional. O aparelho psíquico terá que desempenhar uma dupla tarefa: por um lado zelar pelo vinculo com o mundo externo, exercer as funções que realidade impõe, e por outro, inventar, construir um mundo interno no qual todo o campo do possível e do impossível esta aberto . Este duplo trabalho de simbolização e transformação é viabilizado pelo mecanismo de substituição, com todas as suas potencialidades e seus limites. Não se trata, portanto, de conhecer a realidade e definir os objetos internos ou externos no absoluto, pois eles vão permanecer desconhecidos, mas vislumbrar as ligações que articulam o dentro e o fora .

\footnotetext{
${ }^{9}$ GREEN, André. La lettre et la mort. Paris: Denöel, 2004, p. 188.
} 
A terapia analítica não é um acontecimento pontual ela se desenvolve num tempo mais ou menos longo tendo características processuais. O objetivo do processo analítico é proporcionar um espaço e um tempo para a criação da vida psíquica e permitir o encontro com a negatividade - os aspectos desconhecidos de si; é o re-conhecimento dos impulsos e desejos que foram expulsos no inconsciente que vai permitir que sejam integrados ao núcleo subjetivo . Este trabalho de apropriação ou retorno, trabalho do negativo, diz Green, se dá a partir de um fenômeno intrigante que Freud descobriu e denominou de transferência. Cabe, no entanto, perguntar como a transferência que se instala na relação com o analista pode se tornar um instrumento capaz de conter, apreender, figurar e vincular a negatividade e as forças desligadas das alteridades internas e externas?

A transferência foi descoberta no calor da clínica, quase acidentalmente e a contragosto. De início, o surgimento de desejos surpreendentes dirigidos para o médico, que se tornava repentinamente o objeto de intensos afetos e estranhas representações, aparecia apenas como um obstáculo , uma resistência a ser superada no desenrolar do tratamento; em pouco tempo, contudo, ela foi-se tornando, parte operativa do processo analítico. Em 1900 no caso Dora Freud descreve a transferência como uma resistência ao trabalho de analise, um impedimento para a continuidade da pesquisa da vida psíquica empreendida na atividade da associação livre do paciente . Rapidamente ele percebe que a transferência desloca para a situação analítica expectativas e fantasias ligadas aos desejos infantis que são re-atualizados pelo tratamento psicanalítico. Deve se compreender que cada individuo possui um método especifico e muito particular de conduzir a sua vida amorosa ; é este método que depende da ação combinada de sua disposição inata e das influencias sofridas nos primeiras anos de vida ( as primeiras marcas psíquicas ) que será revelada pela transferência . Ora mais do que um conceito metapsicológico, Freud considera esta intrigante re-atualizacão da vida infantil como um fenômeno clinico que pegá-lo de surpresa e obrigá-lo a rever a sua teoria e a sua técnica . Posteriormente Freud $(1912,1914)$ percebe que a transferência é uma formação psíquica que possui uma economia, uma dinâmica e uma topografia propriamente ditas. No entanto, foi um de seus colaboradores mais próximos o Dr. S Ferenczi que em 1909 tornou este enigmático fenômeno clinico um conceito metapsicológico . Para André Green, a transferência psicanalítica é uma das manifestações da função objetalizante, função psíquica por excelência que trabalha a serviço das pulsões de vida .

Retomando brevemente o desenvolvimentos de Ferenczi lembremos que em 1909 em "Transferência e introjeção" S. Ferenczi aproxima o fenômeno da transferência com o mecanismo de introjeção e o define como sendo um mecanismo de extensão do interesse e 
do investimento libidinal ligado ao deslocamento da excitação e de afetos sediados no núcleo do Ego primitivo em direção ao mundo externo. Ao deslocar a excitação pulsional para os objetos do mundo externo, a introjeção toma posse dos objetos do mundo para introduzi-los gradativamente na esfera do Ego e portanto incluí-los na rede de circulação da atividade anímica e afetiva. O deslocamento de energia acontece através do mecanismo de projeção, que transfere para os objetos externos os excessos de excitação sexual, que se tornam investidos de libido. Segundo Ferenczi, os processos do Ego exploram toda a gama de projeções e introjeções e o mecanismo dinâmico de todo amor objetal e de toda transferência sobre um objeto é uma extensão do ego e acontece pelo mecanismo da introjeção. A introjeção é um dos mecanismos fundamentais da constituição do ego, da vida psíquica e do trabalho psicanalitico. A manifestação da transferência durante o desenrolar do processo analítico atesta para a capacidade do deslocamento do investimento libidinal e vai permitir explorar novas possibilidades de experimentar o mundo. O mecanismo de introjeção é tão fundamental para o desenvolvimento psíquico que segundo Florence Guignard (1997, p91 $)^{10}$ o contínuo jogo que se instala entre os mecanismos de projeção e de introjeção constituem um processo que pode ser chamado de "verdadeira respiração psíquica" pois a fluidez destes intercâmbios entre o dentro e o fora alimentam o crescimento da vida psíquica e permeiam de maneira muito vasta todos as relações do Eu - sujeito com o mundo interno e externo alimentando a rede de representações psíquicas. Esta interação constante constrói tanto o mundo interno do psiquismo infantil como modela as imagens de uma realidade externa sempre em movimento. O estatuto dos objetos é sempre paradoxal, pois será possível conhecer somente objetos que foram re-externalizados após terem sido introjetados; antes desta primeira introjeção que os objetos tanto os externos como os internos, são entes traumáticos, alteridades alheias ao self. A constituição do psiquismo se dá a partir do encontro da criança com um outro humano semelhante que serve de apoio para a transferência dos movimentos pulsionais e é esta transferência que vai ativar a introjecão num movimento de retorno afetivo e vivo.

A tessitura da transferência psicanalítica e seu dinamismo podem ser vistos como uma decorrência praticamente natural dos processos que constituem o Ego e a vida psíquica . Ela adquire a sua força a partir de uma compulsão própria do humano a deslocar, transpor, substituir, transferir e procurar objetos a serem investidos libidinalmente; é no percurso

\footnotetext{
${ }^{10}$ Guignard Florence ( 1997) : A identificação projetiva na psicose e na interpretação in Cartas ao objeto, Imago , RJ , 2002
} 
desta infinita procura que a pulsão adquire a suas qualidades psíquicas apropriando-se de representações e fantasias das alteridades do mundo .

Esta compulsão a deslocar e substituir leva A. Green a postular a existência de uma função psíquica objetalizante, função que promove o deslocamento das excitações pulsionais em direção aos objetos criando vínculos e ligações. Esta função possibilita a extensão do eu e a apropriação dos aspectos inapreensíveis que se manifestam como uma urgência pulsional, excitações excessivas que procuram apaziguamento e satisfação. É a esperança e a antecipação do encontro e da satisfação (a procura do objeto e do prazer) que vão movimentar o deslocamento da libido e promover as infinitas substituições. Cabe, contudo, lembrar que a força da função objetalizante precisará sempre superar uma força que visa ao desligamento e que Green chamou de desobjetalização que trabalha a serviço da pulsão de morte. É este jogo dialético entre as forças de vida e de morte que vai acontecer no processo analítico. A objetalização amarra a excitação a um objeto, cujo vinculo vai ativar a transformação da energia e o processo de simbolização: o fator determinante deste processo é o investimento significativo. Explicando a amplitude da função objetalizante, Green afirma:

"Isto não apenas significa que seu papel é criar uma relação com o objeto (interno ou externo), mas que esta função se revela também capaz de transformar estruturas em objetos, mesmo quando o objeto não está diretamente em jogo. Dito de outra forma, a função objetalizante não se limita às transformações do objeto, mas pode fazer adquirir o estatuto de objeto aquilo que não possui, no início, nem as qualidades, nem as propriedades, nem os atributos do objeto, desde que uma característica essencial seja mantida no trabalho psíquico realizado: o investimento significativo" (Green, 1993, p. $118)^{11}$.

Como este deslocamento das forças acontece dentro da sessão analítica na relação com o analista que se dá basicamente num encontro verbal organizado pela associação livre e a escuta flutuante ? Retornando ao funcionamento do processo analítico, Green afirma que o processo analítico aciona um enquadre que ativa um dispositivo muito particular . $\mathrm{O}$ dispositivo de trabalho acionado pelo método psicanalitico procede a uma estratégia complexa para desencadear um movimento lingüístico que foi nomeado por Freud de associação livre: o divã limita consideravelmente a quantidade da percepção, suprime a visibilidade do objeto e restringe ao mínimo a descarga por via da motricidade. Este dispositivo concentra a força e aumenta a intensidade das pulsões produzido pelo encontro

\footnotetext{
${ }^{11}$ André Green (1993): “ pulsion de mort, narcissisme negatif, fonction desobjetalisante in “ Le travail du negatif”, Paris, Ed de minuit, 1993.
} 
analítico, impulsionando a ligação da força com as representações do objeto (algum aspecto do dispositivo analítico) de tal maneira a promover a transformação em palavras e signos lingüísticos que possa ser organizado num discurso mais ou menos coerente que chamamos de associação livre. Pelo lado do analista a sustentação do enquadre psicanalítico deve ser vista como uma materialização, no espaço e no tempo, da disponibilidade interna do analista em ofertar uma escuta que possa acolher os investimentos e ligar os movimentos pulsionais sempre à procura de objetos capazes de conter a angustia e de promover movimento e transformação. Esta disponibilidade interna primordial, consolidada nos anos de formação do analista, se torna a força de atração da produção expressiva e da transferência dos movimentos pulsionais do paciente . Este dispositivo exprime e aumenta a intensidade da força das pulsões, de tal maneira a impulsionar o deslocamento e a transferência das intensidades estimulando as suas ligações. Uma das funções mais importantes do enquadre psicanalítico é a de receber transferências e de criar investimentos significativos que possam pôr em marcha a função objetalizante .

A. Green descreve três categorias de transferência que estão incluídos no que foi descrito por Freud como transferência psicanalítica. Esta categorização visa a diferenciar os níveis de representação psíquica das forças pulsionais em direção a simbolização . 1.A transferência do somático ao psíquico ${ }^{12}$. : o deslocamento das urgências corporais em afeto , sensações e fantasias . 2. Do psíquico para a linguagem ou pela linguagem: a transcrição destas matérias primas em símbolos e palavras que possam ser comunicadas verbalmente. 3.A transferência da linguagem para o objeto: o transporte desta quantidade em direção a um objeto, o que pressupõe a sustentação da esperança de uma resposta do objeto interno/externo .

Estas transferências co-existem simultaneamente e dialeticamente ao longo do processo analitico, importante para o processo consistirá em detectar as cisões e clivagens . Como existem forças que pressionam pelo desligamento e dispersão do impulso, estas transferências devem, acontecer de ida e volta para permitir a circulação entre o mundo interno e externo numa temporalidade complexa . O discurso analítico esta completamente

\footnotetext{
${ }^{12}$ Para D.W. Winnicott , o psiquismo é a elaboração imaginativa das funções corporais. A pulsão é uma força enraizada no corpo e que ao se manifestar como uma urgência e exige um trabalho psíquico para ser domada e ter uma primeira representação ideativa no ego . No começo para o bebê todas as próprias funções corporais (comer, dormirS, defecar) são vistas como entidades alheias ao self e que de alguma maneira exigem o trabalho do objeto para se tornar próprio, o mesmo poderíamos pensar com relação às manifestações da puberdade .
} 
impregnado pelo passado, sustentado pela antecipação do futuro e se desenvolve no presente a partir do impacto da relação que o enquadre produz ${ }^{13}$.

O vinculo do paciente com o analista (o campo constituído pelos investimentos transferências e contratransferências) materializado no espaço analítico proporciona continência aos movimentos afetivos despertados na sessão, permitindo o fluxo do movimento de transformação das formações psíquicas ao longo do processo analítico. A palavra vai adquirir significado somente quando ela puder ter uma carga afetiva que provem do encontro sempre inquietante com um objeto capaz de responder à demanda de amor implicada na fala.

\section{Considerações finais}

Para André Green existe uma dupla alteridade, a tarefa da psicanálise é de comprender que mesmo sendo enraizada num corpo biológico e vivida a partir de sensações corporais , a sexualidade humana movida pela força da pulsão, será sempre uma forma de alteridade, que implica em si a idéia de uma falta de um objeto. É esta falta de objeto que vai se tornar o pólo de atração da segunda alteridade constitutiva do psiquismo . Esta dupla alteridade forma a matéria bruta do trabalho de psíquico que exige representação e relação . O ego é submetido à pulsão e procura se ligar ao objeto como seu complemento, assim se estabelece uma relação dialética entre a pulsão e o objeto . Nos anos 1990, após ter apresentado um modelo dialético de relação para entender a complexidade da estruturação psíquica $^{14}$, Green começa a falar na dupla “objeto-pulsão"e descreve a relação dialética de complementaridade e oposição que existe entre a pulsão e o objeto: o conceito de pulsão não pode ser pensado sem a noção de objeto, no entanto, mesmo que o objeto seja parte da montagem pulsional, ele também deve ser concebido como externo a esta montagem, para suprir as funções vitais do início do desenvolvimento. Existe, portanto, um paradoxo insuperável entre o objeto e a pulsão: o objeto externo desperta a pulsão e revela a sua demanda, mas é a ativação pulsional que, por sua vez, exige a reposta do objeto e, posteriormente, serão as falhas de adaptação às demandas de pulsão que levarão o sujeito a ter consciência da existência da exterioridade do objeto.

A relação dialética entre a pulsão e o objeto produz um círculo virtuoso: o objeto entra em uma relação com a atividade pulsional, que sai transformada pela resposta proporcionada por

\footnotetext{
${ }^{13}$ Podemos aqui lembrar aqui da definição do sonho proposta pelo Freud ; “ É o substituto de uma cena infantil modificada pela transferência em um modelo recente " S. Freud . l'interpretation des reves , Puf, 1967, pg 465

${ }^{14}$ André Green (1993): “Hegel e Freud: éléments pour une comparaison qui ne va pas de soi” in "Le travail du négatif", Paris, Editions de Minuit.
} 
ele (o objeto), que provoca, por sua vez, no seu retorno, uma transformação do estatuto inicial do objeto. O objeto da necessidade passa a ter o estatuto de objeto de desejo e de demanda. Finalmente ele atingirá a condição de objeto objetivamente percebido (Winnicott) ou o estatuto de objeto absolutamente desconhecido .

\section{BIBLIOGRAFIA}

CANDI , S. T. O duplo limite : O aparelho psíquico de André Green , São Paulo , Escuta , 2010

FERENCZI, S ..Transferencia e introjeção , [1909]. In Escritos psicanalíticos 19091933, Taurus Editora, Rio de janeiro, 1991

FIGUEIREDO, Luis Cláudio. A Questão do Sentido, a Intersubjetividade e as Teorias das Relações de Objeto. Revista Brasileira de Psicanálise, vol. 39, nº 4, 2005.

FREUD , S.. l'interpretation des reves , Paris Puf, 1967

FREUD, S. “A dinâmica da transferência “[1912] In: Obras Completas. São Paulo: Imago, 1969

FREUD, S. Os Instintos e suas Vicissitudes [1915]. In: Obras Completas. São Paulo: Imago, 1969

GREEN, A (1993): "Hegel e Freud: éléments pour une comparaison qui ne va pas de soi" in "Le travail du négatif", Paris, Editions de Minuit.

GREEN, A: " pulsion de mort, narcissisme negatif, fonction

desobjetalisante in "Le travail du negatif", Paris, Ed de minuit, 1993.

GREEN, André. La Causalité Psychique: entre Nature et Culture. Paris: Odile Jacob, 1995.

GREEN, André. De l'objet non unifiable à la fonction objetctalisante [1990]. In:

Propédeutique: la metapsychologie revisitée. Paris: Champ Vallon, 1995.

GREEN, André. La Psychanalyse, Son Objet, Son Avenir [1975]. In: Propédeutique: la metapsychologie revisitée. Paris: Champ Vallon, 1995.

GREEN, André. Idées Directrices Pour une Psychanalyse Contemporaine. Paris: PUF, 2002.

GREEN, André. L'idéalisation du processus et sa problématique veritable. In RFP, Tome LXVIII, Paris, 2004.

GREEN, André. L'Intrapsychique et L'Intersubjetif [2002]. In: La Pensée Clinique. Paris: Odile Jacob, 2002. 
GREEN, André. L'Objet (a) de J. Lacan, sa Logique et la Théorie Freudienne (Convergences et Interrogations). In: Propédeutique: la metapsychologie revisitée. Paris: Champ Vallon, 1995.

GREEN, André. La lettre et la mort. Paris: Denöel, 2004, p. 188.

GUIGNARD F.( 1997) : A identificação projetiva na psicose e na interpretação in Cartas ao objeto , Imago , RJ , 2002

GREEN, A. Répétition, Différence, Réplication en Relisant au Delá du Principe de Plaisir [1970]. In: La Diachronie en Psychanalyse. Paris: Ed. Minuit, 2000,.

LACAN, J. Função e Campo da Fala e Linguagem em Psicanálise [1953]. In: Escritos. São Paulo: Jorge Zahar, 1998.

LACAN, J. O Seminário. Livro XI [1964]. Rio de Janeiro: Jorge Zahar, 1985.

WINNICOTT, D. W. Objets Transitionnels et Phenomènes Transitionnels [1951-1971]. In: Jeu et Realité: l'espace potencial [1971]. Paris: Gallimard, 1972. 